\title{
An obstructed death and medical ethics
}

\author{
Scott Dunbar Cleveland, Ohio, USA
}

\section{Author's abstract}

In this case analysis deception or lying to a dying patient is discussed within the context of different relationships: the relationship between the patient and her family doctor, the relationship between the patient and the surgeon and the relationship between the patient and her family. It is suggested that the principle of veracity is not only a core feature in the patient-doctor relationship but is also fundamentally connected with the basic element of trust between the patient and doctor. The surgeon, in deceiving the patient, even at the request of her husband, betrayed her trust in violating the principle of veracity. The primary responsibility of the surgeon was towards his patient rather than her family. In lying to his patient the surgeon failed to give Mrs fasper something she needed most: respect for her as a person.

Case: 'Truth at last-a case of obstructed death?' Roger Higgs, Fournal of medical ethics 1982; 8: 48-50.

Mr and Mrs Jasper. Both smoked too much. Doctor was called to the house. $\mathrm{Mr}$ Jasper had had five serious episodes of infective bronchitis. Doctor surprised to find Mrs Jasper was the patient he had been called to see. She had severe chest pains and it looked as though she had a severe heart attack. The doctor requested admission to hospital for Mrs Jasper. He was unable to visit her in hospital, though he was in no doubt about his diagnosis. The doctor telephoned the hospital and was told by the house physician that she did not have a heart attack and no one knew the reason for her chest pain.

Later, Mr Jasper called at the doctor's office to tell him his wife was about to have an operation. Meanwhile, $\mathrm{Mr}$ Jasper continued to go to work, and though worried about his wife's condition he did not feel anything out of the ordinary was occurring. He seemed to be in good communication with the hospital staff.

Three weeks later he came to the surgery. His wife was still very ill, nothing further could be done for her and she was about to be sent home. Mr Jasper had been

\section{Key words}

Truth-telling; terminal care; autonomy; beneficence; confidentiality; trust. told his wife had cancer, and 'it was only a matter of time'. 'The only blessing is,' he continued, 'that she knows nothing about it.' When told of his wife's condition, Mr Jasper asked the surgeon not to tell his wife she had cancer and the surgeon agreed.

The family doctor telephoned the hospital and confirmed $\mathrm{Mr}$ Jasper's story. Both $\mathrm{Mr}$ Jasper and his daughter agreed Mrs Jasper should not know the truth about her condition. When the doctor visited Mrs Jasper and approached the subject of her illness $\mathrm{Mr}$ Jasper was adamant that his wife must not know about her condition.

Eventually, Mrs Jasper looked less well and became depressed, but had 'every faith that eventually things would improve'. Mrs Jasper's condition deteriorated. One day, she said to her doctor: 'I can't sleep ... I'm never going to go back to work ... What is wrong with me? Have I got cancer?' The doctor's affirmation was a mixture of tears and hugs.

The atmosphere in the house was stangely relaxed after that. All three spoke, tentatively at first but then quite openly, about the horrors of the five months they had been through. There was no mention of resentment that Mrs Jasper had been told something different by the surgeon, although she seemed to skirt around the subject as if it were in itself unpleasant. She kept on saying: 'They were good though, they were good to me'.

Two days later Mrs Jasper died quietly, her doctor was with her at the time.

After the funeral Mr Jasper came to see the doctor on several occasions. He complained of chest pains; but no physical cause could be found. He was however not easily reassured.

\section{Samuel Gorowitz writes:}

'It seems reasonable that if death is impending, one should want to exert some influence on the mode of one's dying. Just as one wants to be able to influence the major events that shape and constitute a life at earlier stages, one may want to avoid the indignity of having to witness and endure a final stage not as an effective agent, but merely a deteriorating object' (1).

Dr Roger Higgs, author of this case study, asks two 
questions: 'Why did Mrs Jasper die in this way?' and, 'What are the rights and wrongs of the information she was given at first by the surgeon?' The two questions are fundamentally connected. From Higgs's account of the case Mrs Jasper - as Gorowitz puts it in the above passage - endured the indignity of witnessing her dying as a deteriorating object and suffered inter alia the deprivation of being an effective agent throughout the experience(s). What she had to endure for five months after the operation was the direct result of other people; her husband and daughter, the surgeon, each assuming they knew what course of action was in her best interests. Or, alternatively, one could construe the conspiracy of deception created by the trio of comforters as an escape from facing the existential reality of their own death and dying. On this reading of the case, deceiving is done not in Mrs Jasper's best interest but in their own. Mrs Jasper is the stark and painful reminder of something they would prefer to avoid thinking about, prefer not to see, and above all not accept - death and dying. But perhaps this dichotomy is too sharp. Could both readings of the case be valid and the comforters move from the assumed best interests of Mrs Jasper to their own imperceptibly? Let us say the surgeon is competent and is a reasonably caring man, that $\mathbf{M r}$ Jasper loved his wife and the daughter is a dutiful one. Yet, do these three interpretations of the case suffice? I think not. Something more needs to be said. Self-centredness is a natural feature of the human condition. The person each one of us thinks about most is him or her self. The ego, the great grand central 'me' is constantly yapping at our heels and is threatened by the real outside it. Human beings are fantasy-ridden creatures; we create illusions to protect the ego from the world outside it. One of the deepest threats to the cosmos of selfcentredness is any awareness of its total extinction. In this context, Susan Sontag in Illness as Metaphor recognises a symptom but misses the core when connecting lying to cancer patients with our difficulties to come to terms with death in our advanced industrial societies.

In the last five months of her life did Mrs Jasper experience the increasing fragility of her own being and awareness of her non-being? Or, in the last five months of her life did she gradually come to realise that the words spoken to her by her comforters were deceptions; their reassurances contrary to how she felt? Was it with relief that she listened to her own doctor who could see the person in the sufferer, and who spoke truthfully to her about her condition, confirming her own knowledge? Inwardly, did she move from fear of death to quiet acceptance of its inevitability - not death in general but her own particular death? Did her own doctor's truth-telling mixed with tears finally extinguish the flames of deception which had earlier surrounded her and, in so doing allow her to die without resentment towards her comforters? I do not know. The soul of another is a darker forest than one's own.
As noted above, Dr Higgs raises two questions vis-àvis Mrs Jasper:

(i) 'Why did she die in this way?', and

(ii) 'What are the rights and wrongs of the information given to her by the surgeon?

I have suggested that the two questions are fundamentally connected but I want to discuss them separately.

At the outset several points need to be made. Firstly, this case is the stuff that medical ethics or bioethics consultations are made of, in a clinical setting. It draws attention to the distance between theory and practice. It reminds us (if we need to be reminded) of the difference between medical ethics and medical law in an academic context and ethical decision-making in a clinical setting, above all, at the bedside of the patient. Secondly, the case summary provides a substantial amount of information about the patient and her family, as well as the family physician; it provides very little information about the surgeon's relationship with the patient in hospital. I submit the two relationships are not only different in terms of services - primary care and surgical procedure - but in kind. Thirdly, and this follows from the previous point, would the surgeon have lied to Mrs Jasper about the nature of her illness had her husband not asked him to do so? Or, would the surgeon - at the request of Mrs Jasper - have deceived Mr Jasper had he been the patient? And, would a woman surgeon have agreed with $\mathrm{Mr}$ Jasper to deceive his wife? These questions are significant ones. They involve inter alia myths of gender, and in addition, lead one to presume the principle of veracity is not a core value in the surgeon's value system. If it were, it is difficult to comprehend why he would, at her husband's request, lie to his patient who is imminently terminally ill. I am not simply (let alone solely) endorsing a consequentialist view of medical ethics here but emphasising the need for the principle of veracity as a core feature in the patient-physician relationship. The principle of veracity like other ethical principles provides a sense of direction in a medico-ethical situation. Ethical principles resemble guidelines on a map in an unknown landscape rather than reflecting immutable laws of the universe. They are not absolutes. Granted, the surgeon did not know Mrs Jasper would die five months after her discharge from hospital; it could have been a week, four months or nine months but he told her husband it was only a matter of time. The surgeon knew his patient's medical condition and ergo that she was imminently terminally ill.

Concealing the nature of a patient's condition may be justified if it is thought that she/he might commit suicide as a result of learning about the diagnosis and prognosis of the illness. But on the other hand concealing the diagnosis and life expectancy from patients may also be done by doctors because they do not wish to be the bearers of bad news. From this point 
of view deception or lying by the doctor is concerned more with his/her own attitudes, convictions and selfperception rather than with the patient's perception of him/herself and the hopelessness of the medical condition. In this context it is not without interest that there is not a single example in the literature - to date - of a doctor lying to or deceiving an AIDS patient about his/her condition, nor have I encountered an instance in my own clinical experience of an AIDS patient being deceived about her/his diagnosis - even when the patient becomes terminally ill. Why this discrepancy between cancer and AIDS? Could the discrepancy be connected with the infrequency of major surgical intervention in HIV-infected and AIDS patients and the frequency of major surgical intervention in cancer patients? As well as the fact that the infectious disease doctor, unlike the surgeon, becomes in effect the primary care provider and thus may have - other things being equal - the opportunity to know the patient as a person, and his/her value structure?

What criteria do we have to determine whether a particular patient with cancer, such as Mrs Jasper, would commit suicide if she had been spoken to truthfully about her condition? A reliable source in this case would be her family doctor; after all it was he who requested the hospital admission. If the surgeon had got in touch with Mrs Jasper's family doctor, he probably could have learnt about her personal history, her value structure, and her fundamental priorities in life because the family doctor knew her as a person (see case summary). Above all, the surgeon could have learnt whether, on the balance of probabilities, Mrs Jasper could cope with the diagnosis and prognosis or whether she might have committed suicide or attempted suicide. Contact between the surgeon and her family doctor would not have breached the professional principle of confidentiality (telling the patient's husband without her consent did) and could have avoided the perceived need for deception. As it happened it was left to the house physician to deal with Dr Higgs's concern for the condition of Mrs Jasper.

I submit, in the absence of evidence that the patient is likely to commit suicide as a result of being spoken to truthfully about her condition, the principle of veracity should be taken for granted as a fundamental aspect of respect for persons. In a clinical context there are two autonomous agents with common goals and shared burdens; veracity between the two persons is a sine qua non if the goals are to be achieved and burdens are to be shared. Intimately connected with the principle of veracity in a clinical setting is the crucial element of trust. In a fundamental or basic sense 'trust' arises in a patient-doctor relationship because of the inequality between them in knowledge and skills; the patient trusts the doctor to use both for her/his benefit. In a hospital context the doctor can choose to emphasis these differences between her/himself and the patient. Communication between them is then kept to a minimum through the use of the language of medical perception; the language of the single vision. The patient's trust becomes blind trust and the medicine being practised is inappropriate paternalism.

The patient is never allowed to actualise his/herself as a person because the only (or sole) interest the doctor has in the patient are the symptoms manifested in his or her body. Indeed, the doctor may not want to see the patient as a person or to recognise her/his vulnerability, especially when the disease is acute or terminal. The doctor may well know that whatever he/she does the medical condition is irreversible - his skill and knowledge will fail to alleviate the disease process - this can be internalised into personal failure. And/or to see the patient as a vulnerable human being could involve the acknowledgement of his/her own humanity: he/she too is subject to fate and death just like the patient in the bed. The doctor may feel he/she is not able to cope with either or both. In the meantime the patient continues to live in a state of blind trust. Mrs Jasper lived in this state until her family doctor confirmed what she had gradually come to realise, namely, that she was imminently terminally ill: 'Have I got cancer?' The doctor's affirmation verified her intuitive awareness.

Higgs asks: 'What are the rights and wrongs of the information given to her by the surgeon?' What in fact did the surgeon say to Mrs Jasper? According to the case summary he told her she had 'a fungus infection' and that '(he) had removed it.' He did not tell her she had cancer. He did tell Mr Jasper she had cancer, and that, 'it was only a matter of time'. The surgeon deceived Mrs Jasper. Granted, he did so at Mr Jasper's request, but if the principle of veracity had been a core value in the surgeon's value structure, or a mutual value in his relationship with the patient then it is difficult to comprehend why he would have acquiesced to $\mathrm{Mr}$ Jasper's request. Unless, of course, his patient might (or the surgeon thought she might) commit or attempt to commit suicide. But this point has been discussed earlier and certainly from the case summary the patient did not appear to be potentially suicidal. Lying to Mrs Jasper, I submit, was the easiest route for the surgeon to take and he did so, albeit at the suggestion of $\mathrm{Mr}$ Jasper. He could, however, have refused to do so.

The primary or fundamental responsibility of the physician is towards his patient - there is no conflict in this case between the principle of confidentiality and public interest or policy - the family's interests are at best secondary considerations. This is one of the first lessons one learns as a medical ethicist in a clinical setting; another accompanying lesson is that the patient's and the family's interests do not always coincide.

The surgeon lied to Mrs Jasper about her medical condition. Mr Jasper, and later their daughter, approved and acted on the initial deception. Indeed, Mr Jasper thought the deception or lying to be a 'blessing' because he opined his wife could not cope with the news, the bad tidings, or quite simply, being 
spoken to truthfully about her medical condition. Probably the surgeon thought so to. But probabilities apart, we know he deceived Mrs Jasper and deceiving, as already noted, is a form of lying. Does lying to a cancer patient, in this case Mrs Jasper, reflect the anxieties of the healthy? Ian Kennedy is pertinent on this issue of lying to cancer patients:

'All the doctors in the study, Relationships between Doctors and Patients, firmly believed that the great majority of patients should not be told they had cancer, nor be given their prognosis unless it was favourable. The patients were to be given only as much information as was compatible with the retention of hope, whether justified or not. The doctors realised that some patients may indeed have wished to know the truth, but, since without asking them they could not knuw which patients, they managed the problem by not telling anyone, unless a patient specifically demanded the truth... . Everything proceeds on the basis of the particular doctor's judgement. It all boils down to the doctor being good, gentle and kind. It would be nice if all our doctors were like this. But, just in case, can we not have some more certain guarantees that our interests, as defined by us, may be allowed to prevail? The device of the therapeutic privilege pays lip service to the principles of truth-telling and selfdetermination, while it creates a discretionary exception which is quite capable of swallowing these principles when the doctor decides the occasion requires it' (2).

Ethics is not an extension of medical knowledge and skills.

The point(s) at issue here is neither medical skills nor knowledge but ethics contextualised in the practice of medicine. In addition to the ethical concepts discussed above two further concepts or ethical principles need to be looked at in this case, namely, self-determination, or autonomy, and beneficence (3). The concept of autonomy is grounded in the philosophical doctrine of respect for persons; indeed one might say respect for another's right to selfdetermination or respect for her/his autonomy concretises the doctrine of respect for persons. The rights and wrongs (as Higgs puts it) of the information given to Mrs Jasper by the surgeon include - above all - a conflict between respect for her as an autonomous agent (the principle of autonomy) and beneficence or the principle of beneficence. A medical colleague complained to me on several occasions about the concept of autonomy; since it cannot be defined it has (she said) little, if any value, in dealing with ethical dilemmas in particular cases. Despite her frustration with the concept of autonomy her work as a clinician exemplified an intuitive awareness and sensitivity of the otherness of others; respect for persons in his or her particularity was no mere philosophical abstraction, both were actualised in each consultation. Beneath the language of words there is the language of feeling expressed by touch. My colleague's medical knowledge and skills did not distance her from the patient because the art of healing combined 'seeing' and 'responding' to the needs of the other person.

I sympathise with her frustration with ethical concepts; medical ethics qua principles or rules. There are no ethical recipe books that can be used or consulted in particular situations to resolve ethical dilemmas in a clinical setting. In a wider context the moral life of an individual is more intimately connected with his/her consciousness (qualities of consciousness and levels of awareness) than it is with subscribing to a set of ethical rules or principles. And, as I have suggested earlier in this paper the purpose of ethical principles lies in their capacity to provide a sense of direction; they resemble guidelines on a map of an unknown landscape. Aristotle's distinction between theoretical knowledge and practical knowledge is useful here, especially when he reminds us that we ought not to expect the precision of the former (science) from the latter (ethics qua action). Suffice to say an autonomous person is the author of her/his own mode of existence and inter alia part artificer of his/her moral world. Respect for autonomous persons is implemented in adopting the principle of autonomy as a guide about how to treat autonomous agents. And, as noted above in a clinical context there are two autonomous persons: the patient and the doctor.

The ethical concept of beneficence (and nonmaleficence) is found in the Hippocratic Oath:

'I will apply measures (treatment) for the benefit of the sick according to my ability and judgement; I will protect them from harm or injustice.'

The primary responsibility of the doctor is to her/his patient - to benefit the patient. And from the responsibility to benefit the principle of beneficence flows. The doctor acts qua doctor to prevent evil or harm, as well as to remove evil and promote the wellbeing of his/her patient.

Against the above background what can be said about Higgs's question: 'What are the rights and wrongs of the information given to her (Mrs Jasper) by her surgeon? In the first place, he deceived her by telling her she had a fungus infection and that he had removed it. He did not tell her she had cancer. Though the surgeon's deception was done at the request of $\mathrm{Mr}$ Jasper, nonetheless, the fact remains it was his act and therefore his responsibility. Secondly, without her consent he informed her husband she had cancer and that it was only a matter of time. Thirdly - and above all - he failed to respect Mrs Jasper as a person, as an autonomous agent, by violating her autonomy or right of self-determination.

The crucial crisis in this case is the conflict between the two ethical principles of beneficence and autonomy. As is emphasised above, the primary responsibility of the doctor is to his patient; not to the relationship between the husband and wife, or between 
the daughter and her mother and father. The surgeon could have respected the principle of beneficence without violating his patient's autonomy and the conflict between the two could have been avoided if he had spoken truthfully to Mrs Jasper about her physical condition. Further, the principle of veracity would have preserved the principle of confidentiality and Mrs Jasper's trust in the surgeon would not have been abused by him. Thus, I can only conclude from this analysis of the case that the information given to Mrs Jasper was wrong from an ethical or moral point of view and imprudent from a professional one.

What about Higgs's question: 'Why did she have to die in this way?' Mrs Jasper died, or more precisely lived and endured five months of 'horror' (her husband and daughter experienced horror also), 'depression' and anxiety before she died as a direct consequence of the initial deception, or lying, by the surgeon. It could have been otherwise. To cause his patient horror, depression, and anxiety in the absence of benefit is to cause harm and thus to fail to respect the principle of non-maleficence. Finally, the trio of comforters failed to see the person in the sufferer.

One of the worst experiences a human being can have is the experience of abandonment. We can abandon one another in different ways. Mrs Jasper was abandoned through betrayal of trust and deception; a combination of the two caused her comforters to become remote from her and for the same reason she became remote from them. The comforters could not bear (or thought they could not bear) to take the reality of her existence in a dying state; she was with her family but alone, inhabiting an inner world of private doubts, grief and suffering.

A certain dissatisfaction remains after completion of this analysis. Let me put it in the form of a question: 'Is there not a need to include truth-telling to patients in a Code of Medical Practice?' Such a clause in a Code of Medical Practice would remove the alleged need to deceive or lie on the part of the doctor and relieve the patient from additional suffering, particularly, a dying patient such as Mrs Jasper. A voice says: 'But what about people who don't want to be treated autonomously?' I do not doubt there are such people but may they not be much fewer than doctors suppose? On this point Gorowitz speaks for the majority of us:

'It seems reasonable that if death is impending, one should want to exert some influence on the mode of one's dying. Just as one wants to be able to influence the major events that shape and constitute a life at earlier stages, one may want to avoid the indignity of having to witness and endure a final stage not as an effective agent, but merely a deteriorating object' (1).

Footnote: "After the funeral, $\mathrm{Mr}$ Jasper came to see the doctor on several occasions. Once he complained of chest pains. There was no physical cause to be found.... He was, however, not easily reassured'. The Ancient Greeks spoke of the Erinyes who punished the living because of their crimes or injustices against the dead. The Erinyes are not vindictive, their punishment is both impartial and impersonal.

Scott Dunbar, PhD, Postgraduate Diploma in Medical Law and Ethics (KCL), is a Fellow in Bioethics, Cleveland Clinic Foundation, Ohio, USA.

\section{References}

(1) Gorowitz S. Doctors' dilemmas. New York: Oxford University Press, 1982:153.

(2) Kennedy I. The unmasking of medicine. London: George Allen and Unwin, 1982:86-87.

(3) For an excellent general discussion of the arguments used by physicians to justify the practice of lying or deceiving dying patients, see Bok S. Lying, - moral choice in public and private life. Hassocks, Sussex: Harvester Press, 1978: particularly chapter XV, Lies to the sick and dying. 